\title{
Dynamic grid fault analysis in wind power plant with DFIG by using supervisory control and data acquisition (SCADA) viewer
}

\author{
Nduwamungu Aphrodis ${ }^{1 *}$, Ntagwirumugara Etienne ${ }^{2}$, Utetiwabo Wellars ${ }^{3}$, Mulolani Francis $^{4}$ \\ ${ }^{1}$ Africa Centre of Excellency in Energy for Sustainable Development, University of Rwanda, Rwanda \\ ${ }^{2}$ Africa Centre of Excellency in Energy for Sustainable Development, University of Rwanda, Rwanda \\ ${ }^{3}$ School of Education,University of Rwanda, Rwanda \\ ${ }^{4}$ Department of Electrical and Electronics Engineering, Copperbelt University, Kitwe, Zambia
}

\begin{abstract}
Faults in electrical power systems are among the key factors and sources to network disturbances, however control strategies are among key faults clearing techniques for the sake of safe operational mode of the system. Some researchers have shown various limitations of control strategies such as slow dynamic response, inability to switch Off and On network remotely and fault clearing time. For a system with wind energy technologies, if the power flow of a wind turbine is interrupted by a fault, the intermediate-circuit voltage between the machine-side converter and line-side converter will fall in unacceptably high values. To overcome the aforementioned issues, this paper used a Matlab simulations and experiments in order to analyze and validate the results. The results showed that fault ride through (FRT) with SCADA Viewer software are more adaptable to the variations of voltage and wind speed in order to avoid loss of synchronism. Therefore at the speed of $12.5 \mathrm{~m} / \mathrm{s}$ a wind produced a rated power of $750 \mathrm{~W}$ and remained in synchronization before and after a fault created and cleared but worked as generator meanwhile at speed of $3.4 \mathrm{~m} / \mathrm{s}$ wind disconnected from grid and started working as a motor and consumed active power ( $\mathrm{P}=-25$ watts) and voltage dip at $100 \%$.For the protection purpose, the DC chopper and crowbar should be integrated towards management of excess energy during faults cases.
\end{abstract}

\section{Introduction}

The worldwide energy consumption and demand are increasing, very quickly due to the rapid growth of population, industrialization and modernization [1].

In response to this growth in demand, different technologies are being applied and implemented in different countries for the purpose of electricity diversification and to increase the rate of electrification. Integrating renewable energy technologies into the utility grid is one of the most common methods due to different reasons such as low maintenance requirements, cost saving, economic and environmental, and storage capabilities [2].

The Wind technology is among the renewable energy technologies where usable electricity is produced from the kinetic energy of the wind through wind turbines and generators.

The doubly fed induction machines are electric generators and electric motors that have windings on both the stator and the rotor. Both windings are capable of transferring active power between the shaft and electrical system. The stator winding is usually directly connected to the three phase grid, while the rotor winding is connected to the grid through power electronic converters.
Doubly fed machines are usually applied in applications requiring variable shaft speed of the machine in a limited range around the synchronous speed [3].

Due to the variable nature of the wind speed, the reliable and dynamic operation of the power grid networks containing wind farms is a significant challenge for both researchers and grid operators. The requirements for voltage and frequency variation within the permissible range given by a country or region's grid codes and standards must be met in order to prevent the cessation or suspension of power grid's service during the time period of dynamic power grid disturbances [4].

The aim of this paper is to analyse the dynamic behaviour of a grid connected wind power plant with a doubly fed induction generator through Matlab simulation and experimental verifications using SCADA VIEWER and Active Servo software package. The paper is organized as follows: 1. Introduction, 2.Review of DFIG wind turbine 3.System modelling, 4.Results and Discussion, 5.Conclusion.

\section{Review of DFIG wind turbine}

In its steady-state operation a doubly-fed induction generator generates active power which is fed to the grid. The production and consumption of active power may not be balanced certain circumstances. This results in

Corresponding author: aphronduwa@gmail.com 
changes in the active power input, voltage regulation and frequency stability [5].

The dynamic behaviour of wind power plant involves short-term pronounced changes in the mains voltage brought about by grid faults. The requirements for wind power plants in different countries deal with what is termed fault ride-through (FRT), as well as dynamic voltage regulation and associated rise times. The dynamic behaviour of wind power plants was analysed by different researchers when it is synchronized to the utility grid. An overview of their results show that the DC link will be overloaded due to the lack of a DC chopper and crowbar [6].

The output of a wind power plant is provided by the blades after being converted from kinetic energy into mechanical energy [7].

The Permanent Magnetic Doubly Fed Induction Generator (PMDFIG) was used to solve an issue of voltage fluctuation but still the poor communication issue was still there (the grid faults lead to the voltage sag in short duration at the feed point) [8].

The communication issue was little bit solved but the overloading issue for intermediate circuit located between machine side controller and line side controller isn't used [9].

The voltage dips is classified based on magnitude and phase with different controllers even if the excess energy is still not solved [10].

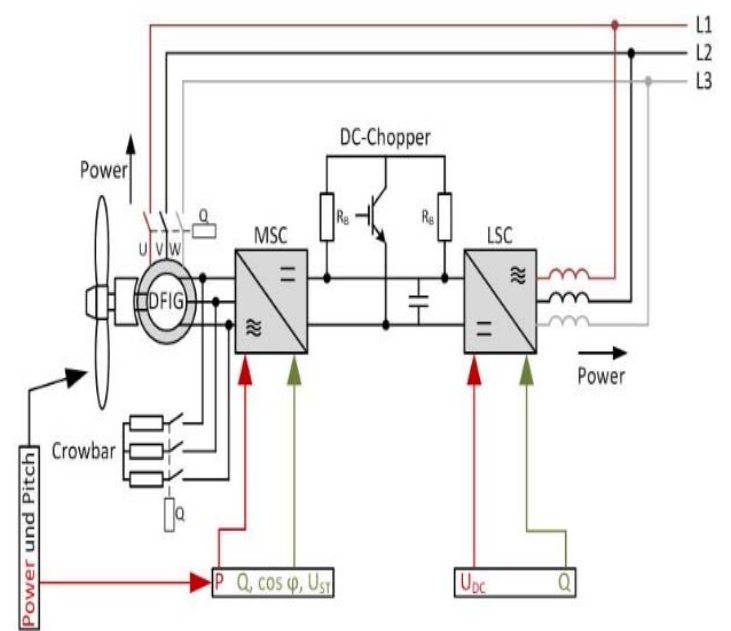

Fig. 1.Schematic of wind with DFIG

The utility grid containing wind power plants requires a tangible method for controlling any disturbance with the best fault clearing time. The Fault Ride Through (FRT) is one of them and focus on differently sized voltage dips on a wind power plant so that the wind farm can stay synchronized in any circumstance in order to increase the reliability and power quality [11].

\section{Design modelling and operating characteristics of DFIG wind turbine}

Figure 1 is the schematic diagram of the system simulated in MATLAB/ Simulink. In the steady state, Figure 1 shows that reactive power can be supplied via the machine-side converter to the generator. During a voltage dip, reactive current can also be fed via the line-side converter to guarantee the required dynamics. Because the line-side converter is primarily responsible for regulating the intermediate-circuit voltage, however, only a limited reactive current can be fed in this case.

\subsection{Analysis and validation of the designed model}

In order to analyse the dynamic utility grid fault, MATLAB/Simulink has been used to design the model as shown in figure 1. Validation of the model has been carried out using the experimental step up as shown in figure 2.However, the integration of renewable energy (wind) into electrical network creates problems in case of grid connected and islanded operational mode. Modern wind plants need to help the utility grid in the way that they respond to breakdowns. This means that they need to be able to carry out a number additional functions such an automation technology. The modelling of this model had been designed by using MATLAB/Simulink and validated by using an experimental set up.Figure 2 is composed of the following devices: Dynamic grid fault simulator (used to simulate voltage dips in three-phase networks, thus making it possible to study the response of devices connected downstream with different features), control unit for DFIG (Modern wind turbines use doublyfed Induction generators or permanent magnet synchronous generator to supply power to the utility grids. The SCADA Viewer allows the control and operation the principle concepts of wind power plants through different scenarios. The control unit makes it possible to emulate and study all scenarios of practical relevance. The included software enables easy operation and convenient visualization of measured values. Isolating transformer for wind power plants with its switch (Three-phase transformer for coupling the doubly-fed wind power plant to the supply network),incremental encoder used for controlling the variation of angular speed, The servomachine test bench is a complete testing system for examining electrical machines and drives. It consists of a digital controller, a brake and the Active Servo software (Active Servo is a program for recording characteristics of machines and for determining dynamic and static operating points. It emulates seven different loads (flywheel, pump etc.) for which the parameters can be individually configured). The power supply for the electrical machines is the utility grid and can supply DC, $\mathrm{AC}$ and three phase machine and also the excitation for the synchronous machine. The DC chopper is located between the Machine Side Converter (MSC) and Line Side Converter (LSC) so when the power flow is perturbed due to the fault or another technical problem the intermediate circuit voltage increases to unacceptably high values and the excess energy is dissipated via a DC chopper. However, in the event of a serious fault, the DC chopper might no longer suffice to limit the intermediatecircuit voltage. In such situations, an AC crowbar should be used instead. 


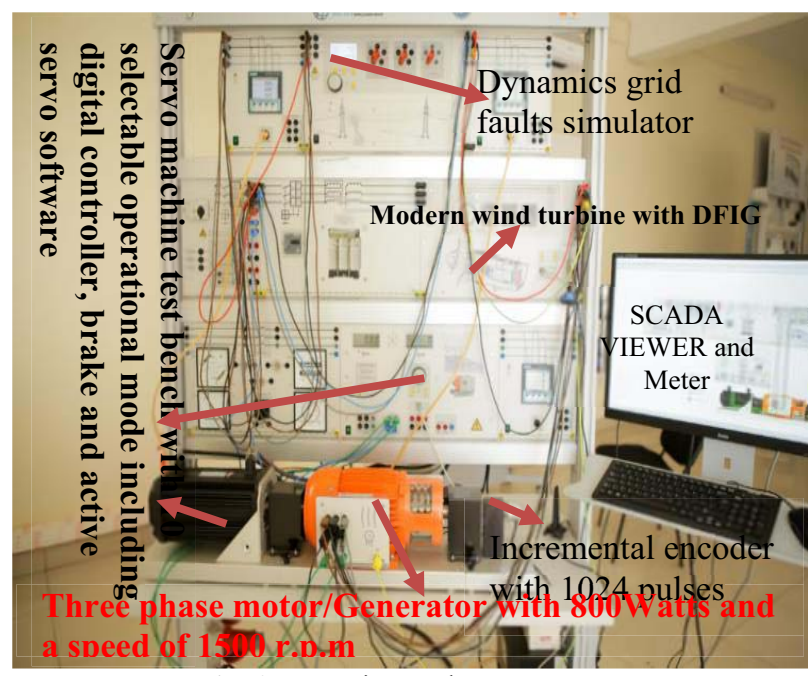

Fig. 2: Experimental set up

\section{Results and discussion}

Table 1.Experimental data recorded

\begin{tabular}{|c|c|c|c|c|c|c|c|}
\hline $\begin{array}{c}\mathrm{N} \\
{[\mathrm{rpm}]}\end{array}$ & $\begin{array}{c}\mathrm{M} \\
{[\mathrm{Nm}]}\end{array}$ & $\begin{array}{c}\text { Pmec } \\
{[\mathrm{W}]}\end{array}$ & $\begin{array}{c}\text { Pgen } \\
{[\mathrm{W}]}\end{array}$ & $\begin{array}{c}\text { Pls } \\
{[\mathrm{W}]}\end{array}$ & $\begin{array}{c}\text { Ptot } \\
{[\mathrm{W}]}\end{array}$ & $\begin{array}{c}\text { Speed } \\
{[\mathrm{m} / \mathrm{s}]}\end{array}$ & $\begin{array}{c}\text { Voltage } \\
\text { dip }\end{array}$ \\
\hline 1902 & 6 & 1201 & 675 & 47 & 750 & 12.5 & $0 \%$ \\
\hline 1897 & 4.8 & 915 & 501 & 14 & 520 & 10.5 & $20 \%$ \\
\hline 1667 & 3 & 530 & 274 & -62 & 212 & 8.5 & $40 \%$ \\
\hline 1378 & 2 & 297 & 161 & -100 & 61 & 7 & $60 \%$ \\
\hline 1281 & 1.8 & 239 & 127 & -104 & 22 & 6.5 & $100 \%$ \\
\hline 1038 & 1.1 & 127 & 56 & -108 & -53 & 5.2 & $100 \%$ \\
\hline 911 & 0.9 & 80 & 25 & -102 & -80 & 4.5 & $100 \%$ \\
\hline 756 & 0.4 & 37 & 0 & -2 & -25 & 3.4 & $100 \%$ \\
\hline
\end{tabular}

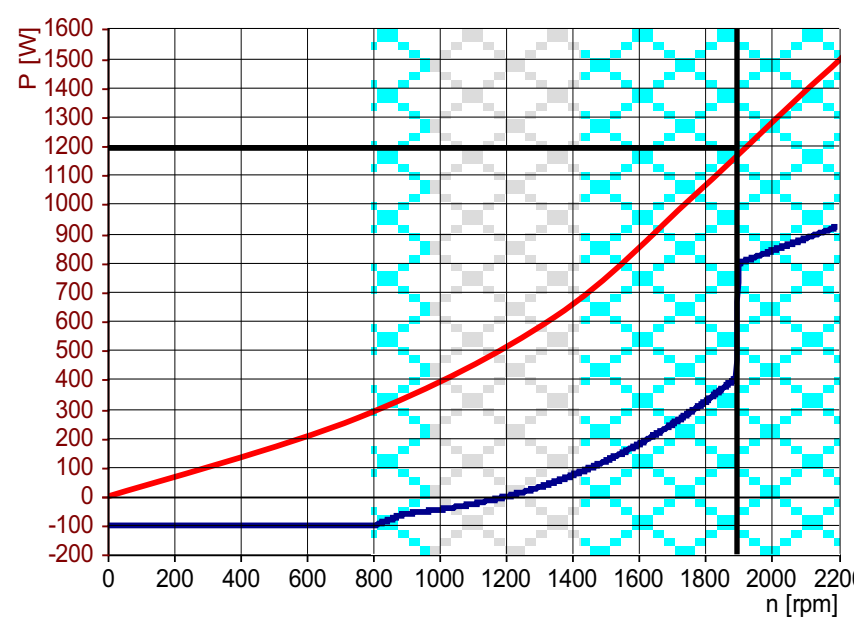

Fig. 3. Results of wind with a speed of $12.5 \mathrm{~m} / \mathrm{s}$

Table 1 showed the data recorded during conducting an experiments and analyzing different scenarios focusing on variation of parameters namely: voltage dip, inertia moment, rotation speed, mechanical power, power at generator side, total power and power at line side.

Figure 3 illustrated the figures obtained when speed $=12.5 \mathrm{~m} / \mathrm{s}$ total power $\left(P_{\text {tot }}\right)=750 \mathrm{~W}$,Mechanical power $\left(P_{\text {mec }}\right)=1201 \mathrm{~W}$, Rotation speed $N=$
1902 r.p. $m$ were varying meanwhile the power was constant and voltage dip $=0 \%$, Power at the line $\operatorname{side}\left(P_{l s}\right)=47 \mathrm{~W}$ and Power at generator side $\left(P_{\text {gen }}\right)=$ $673 W$ the results means that the wind power plant is working as a generator.

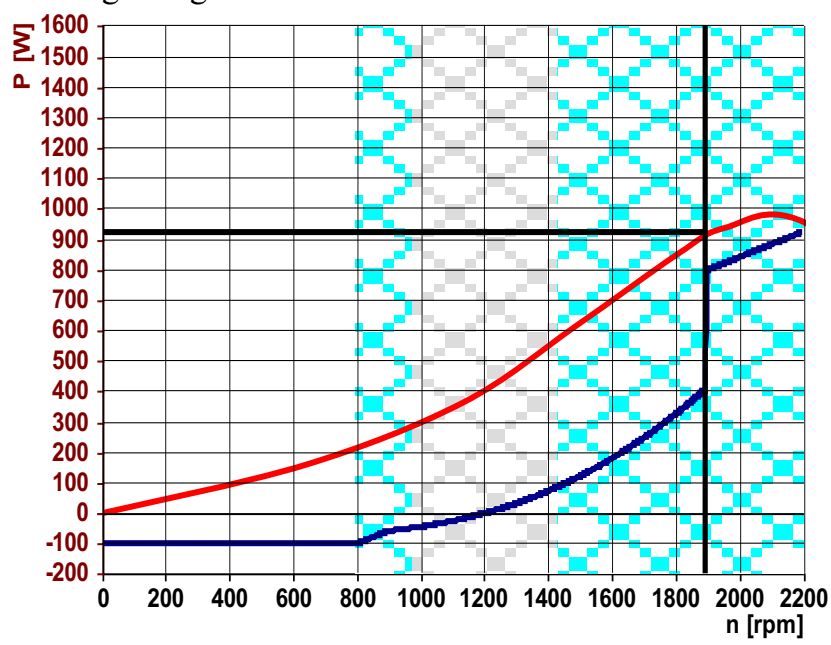

Fig. 4. Results of wind with a speed of $10.5 \mathrm{~m} / \mathrm{s}$

Figure 4 illustrated the figures obtained when speed $=10.5 \mathrm{~m} / \mathrm{s}$, Total power $\left(P_{\text {tot }}\right)=514 \mathrm{~W}$, Mechanical power $\left(P_{m e c}\right)=915 \mathrm{~W}$,Rotation speed $(N)=$ $1897 r . p . m$, voltage dip $=20 \%$, the power generated by wind $=14 \mathrm{~W}$ and power at generator $\operatorname{side}\left(P_{\text {gen }}\right)=501 \mathrm{~W}$

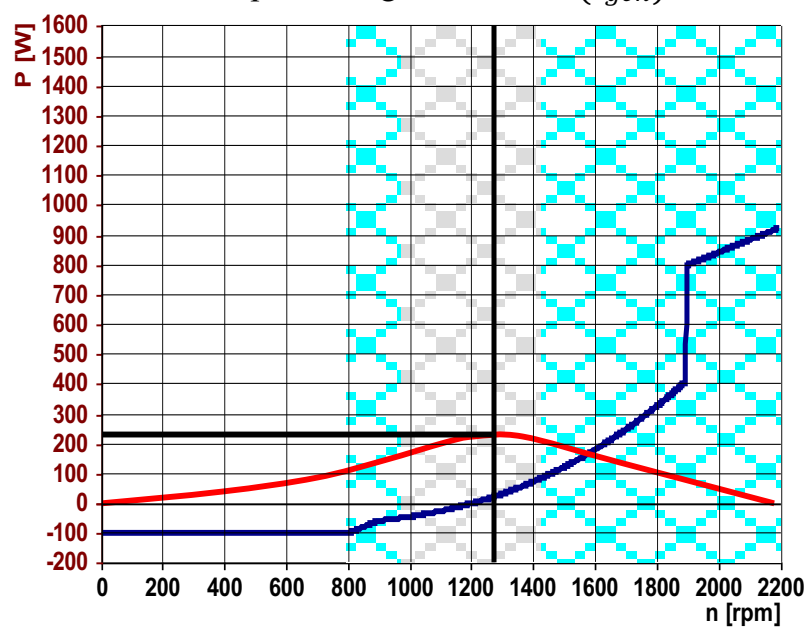

Fig. 5. Results of the wind with a speed of $6.5 \mathrm{~m} / \mathrm{s}$

Figure 5 showed the figures obtained when speed $=6.5 \mathrm{~m} /$, Total power $\left(P_{\text {tot }}\right)=22 \mathrm{~W}$, Mechanical power $\left(P_{m e c}\right)=240 W$, Rotation speed $N=1275$ r.p. $m$ and voltage dip $=100 \%$ and the wind was working as motor and consumed power which was $=-104 \mathrm{~W}$ and the speed was increasing meanwhile the power was constant.

Figure 6 showed the values obtained when speed= $5.2 \mathrm{~m} / \mathrm{s}$, Total power $\left(P_{\text {tot }}\right)=-53 \mathrm{~W}$, Mechanical power $\left(P_{\text {mec }}\right)=129 \mathrm{~W}$, Rotation speed $(N)=$ 1040 r.p. $m$, voltage dip $=100 \%$ and Power at line side $\left(P_{l s}\right)=-102 W$ and power at Generator side $\left(P_{g e n}\right)=$ $57 W$ at this stage the wind was in reverse way because of negative power and the speed was varying meanwhile the power was constant. 


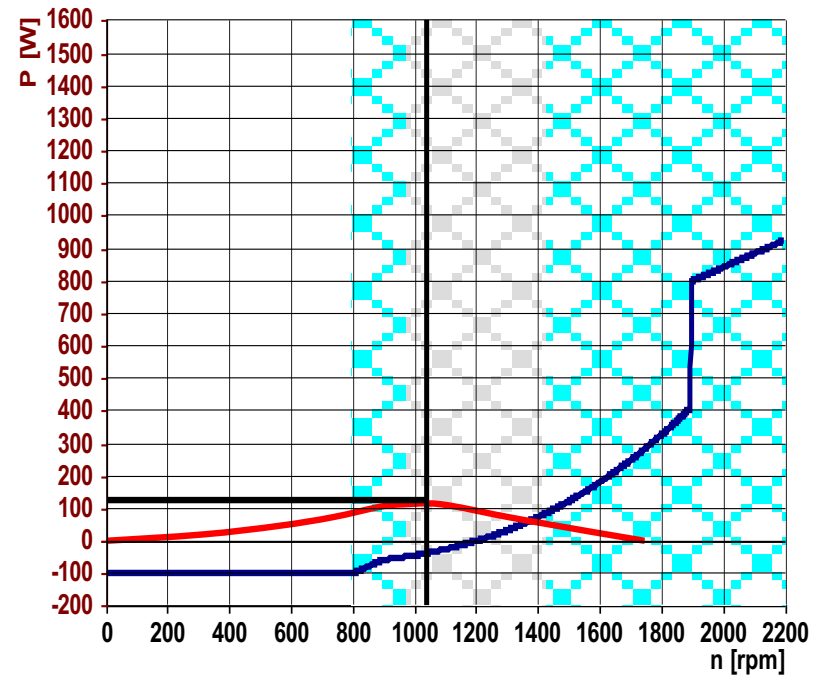

Fig. 6. Results of wind with a speed of $5.2 \mathrm{~m} / \mathrm{s}$

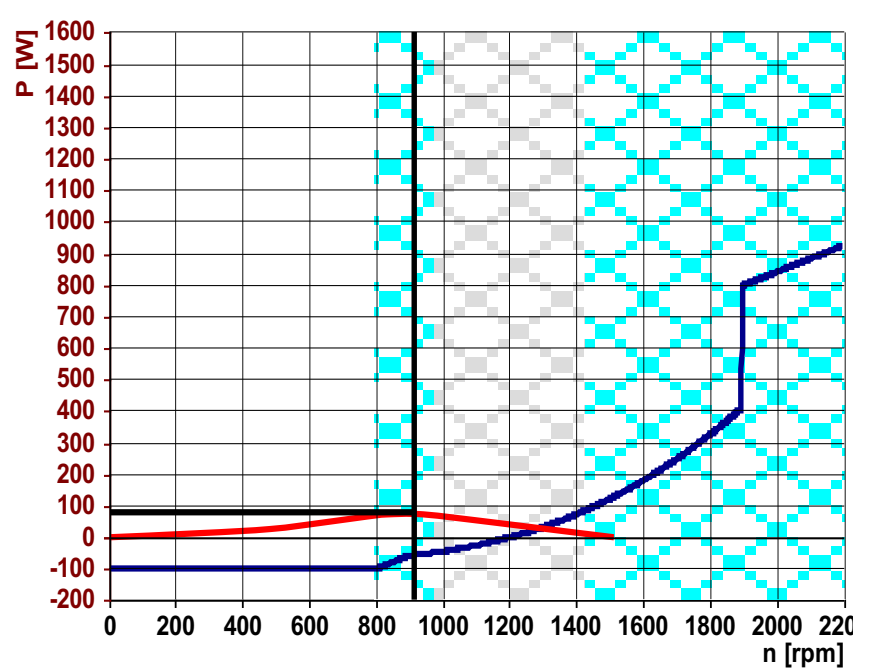

Fig. 7.Results of wind with a speed of $4.5 \mathrm{~m} / \mathrm{s}$

Figure 7 illustrates the figures obtained when speed $4.5 \mathrm{~m} / \mathrm{s}$, Total power $\left(P_{\text {tot }}\right)=-80 \mathrm{~W}$, Mechanical power $\left(P_{\text {mec }}\right)=80 \mathrm{~W}$, Rotation speed $(N)=911$ r.p.m, voltage $\operatorname{dip}=100 \%$, Power at line side $\left(P_{l s}\right)=-100 \mathrm{~W}$ and power at generator $\operatorname{side}\left(P_{\text {gen }}\right)=25 \mathrm{~W}$ and the wind was working as a motor instead of working as generator because of voltage dip.

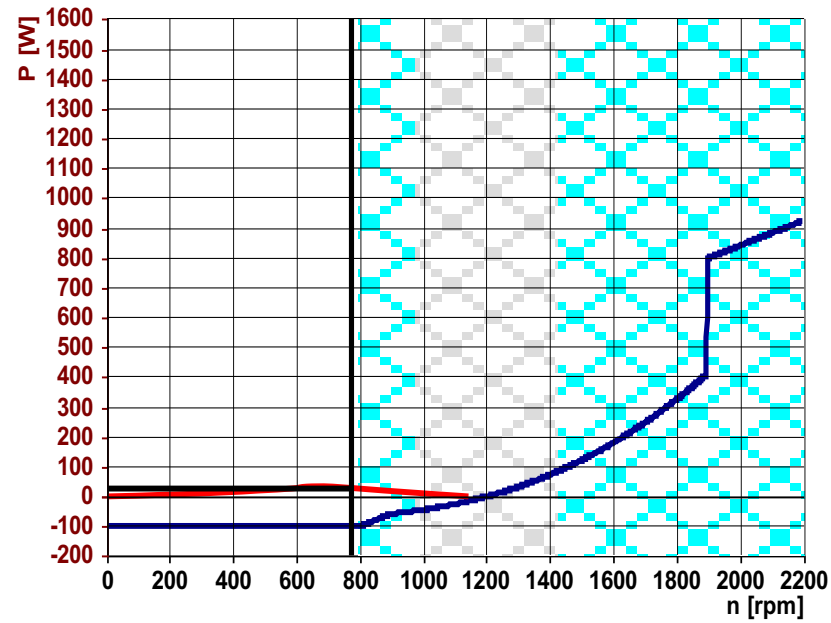

Fig. 8. Results of wind with a speed of $3.4 \mathrm{~m} / \mathrm{s}$
Figure 8 showed the figures obtained when speed $3.4 \mathrm{~m} / \mathrm{s}$, Total power $\left(P_{\text {tot }}\right)=25 \mathrm{~W}$, Mechanical power $\left(P_{\text {mec }}\right)=37 \mathrm{~W}$, Rotation speed $(N)=756$ r.p.m, voltage dip $=100 \%$, Power at line side $\left(P_{l s}\right)=$ $-25 W$ and the wind turbine was unsynchronized because the speed was too low and consumed power as motor because of voltage dip.

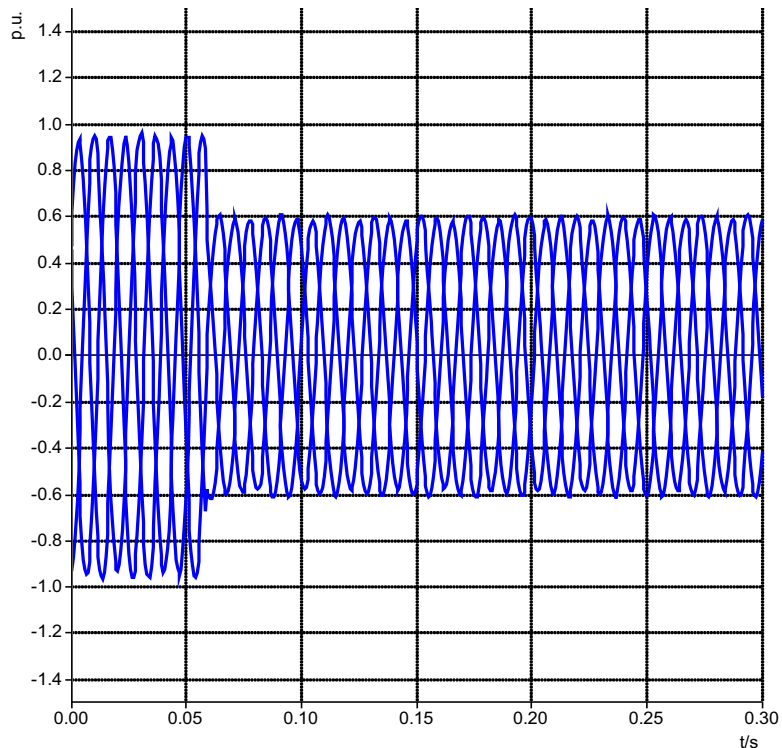

Fig. 9.Instantaneous voltage on grid side

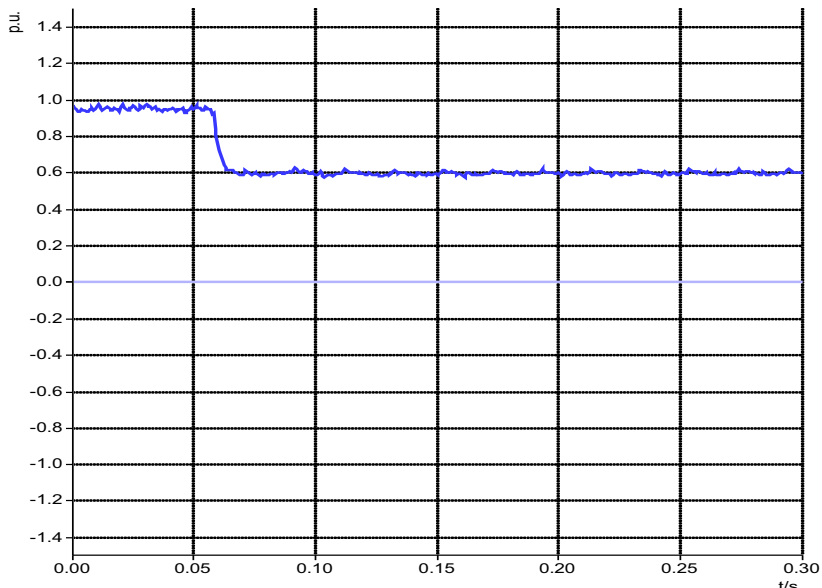

Fig. 10. Voltage on direct and quadrature axes

Figure 9 illustrates the figures obtained when instantaneous values of the main voltage $U_{\text {grid }}$ and $\mathrm{t}=0.005 \mathrm{~s}$ a fault has been created and cleared at time of 0.30 s via SCADA software and remain synchronized with a capability of FRT.

Figure 10 displayed the voltage $U_{\text {grid }}$ measured for direct and quadrature axis in the positive sequence and at 0.05 a fault occurred in network.

Figure 11 displayed the current $I_{\text {grid }}$ measured for direct and quadrature axis in the negative sequence and their values are almost equal to zero after being subjected to the disturbance at $\mathrm{t}=0.054$ seconds. 


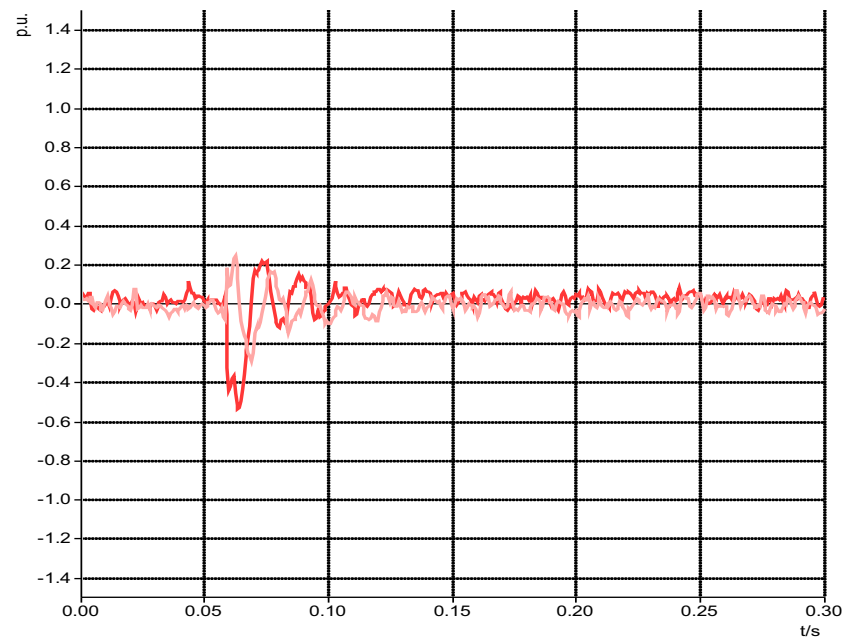

Fig. 11.Current in direct and quadrature axes

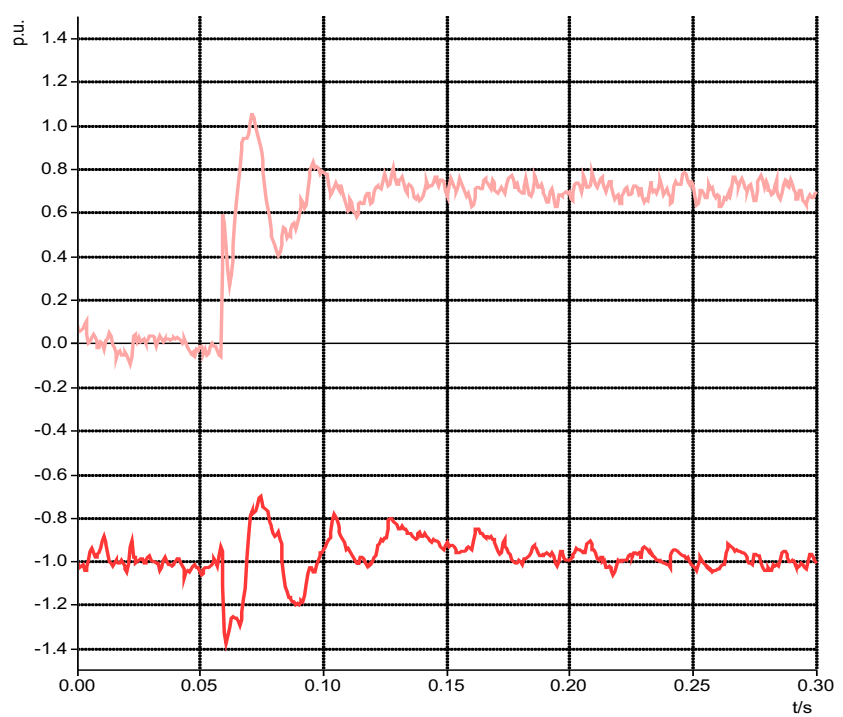

Fig. 12. Current for direct and quadrature axis in the positive sequence

Figure 12 displayed the current $\mathrm{I}_{\text {grid }}$ measured for direct and quadrature axes in the positive sequence. Therefore, the direct current has been increased at $\mathrm{t}=0.054$ seconds meanwhile the quadrature axis current is almost zero before and after subjected to the disturbance.

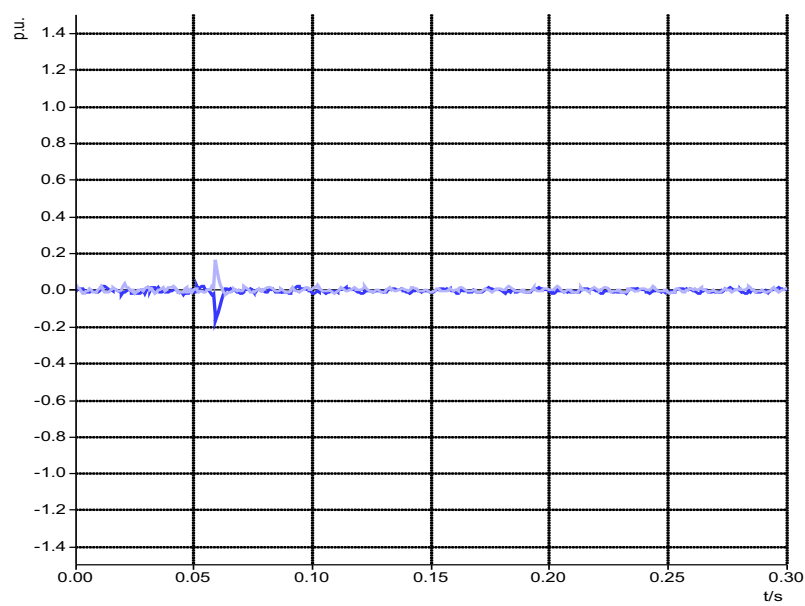

Fig. 13. Voltage in direct and quadrature axes
Figure 13 displayed the voltage $\mathrm{U}_{\text {grid }}$ measured for direct and quadrature axis in the negative sequence. The voltage in direct axis and voltage in quadrature axis are equal to zero in per unit as shown in figure 13.

\section{Conclusion}

The simulation and experimental results in this paper showed that the fault ride through (FRT) capability with SCADA VIEWER software are more adaptable to variations of voltage dip and wind turbine speed in order to avoid loss of synchronism.Even though the speed of the wind turbine decreased up to $3.4 \mathrm{~m} / \mathrm{s}$ followed by lost of synchronism,commenced to operate as a motor and consummed active power which was equal to -25 watts.

For protection purpose, the DC chopper and crowbar should be integrated in wind energy technologies in order towards management of excess energy during fault cases, this has been seen at $\mathrm{t}=0.054$ seconds when a fault created in figure 12 and 13.

Moreover, The SCADA Viewer software displayed its effectiveness and competitiveness during fault clearing time ( $\mathrm{t}=0.054 \mathrm{~seconds})$ at the speed of $12.5 \mathrm{~m} / \mathrm{s}$ and produced 750 Watts as rated capacity but voltage dip was $0 \%$ and stayed synchronized before a fault creation meanwhile after fault created it was still synchronized to the utility grid.

Furthermore, it revealed that it is feasible to control and automation a network remotely.

The percentage of voltage decreased from $0 \%$ up to $100 \%$ of total voltage in every fault case while the current increases depends upon type of sequence.

Nevertheless in direct axis, the voltage remained lies at the direct level and in positive sequence which clearly indicates that the voltage decreases in percentage in each fault cases.Thus, the voltage and current do neither exhibit any negative sequence nor any symmetric components.

Future work will be based dynamic grid fault analysis in wind power plant with DFIG by using an artificial intelligence instead of SCADA Viewer.

\section{Acknowledgment}

The authors would like to express our gratitude to the World Bank in collaboration with the government of Rwanda under the African Center of Excellence in Energy for Sustainable Development based at the University of Rwanda.

\section{References}

1. Kawady, T. A., Mansour, N. M., \& Taalab, A. I. (2010). Wind farm protection systems: state of the art and challenges. Distributed Generation, 265-288.

2. Qiu, Y., Feng, Y., \& Infield, D. (2020). Fault diagnosis of wind turbine with SCADA alarms based multidimensional information processing method. Renewable Energy, 145, 1923-1931.

3. Vittal, V., McCalley, J., Ajjarapu, V., \& Shanbhag,U. V. (2009). Impact of increased DFIG 
wind penetration on power systems and markets. PSERC publication, 9.

4. Hansen, A. D., Cutululis, N. A., Markou, H., Sørensen, P. E., \& Iov, F. (2010). Grid fault and design-basis for wind turbines-Final report.

5. Lopes, J. A. P., de Vasconcelos, M. H. O. P., Santos, R. L., \& Fonseca, J. (1999). Estudos de impacto eléctrico da integração de produção eólica adicional nas redes eléctricas da República de Cabo Verde: caso de Santiago. Proceedings ELAB 99.

6. Chakraborty, A., Kumar, S., Tudu, B., \& Mandai, K. K. (2017, December). Analyzing the dynamic behavior of a DFIG-based wind farm under sudden grid disturbances. In 2017 international conference on intelligent sustainable systems (ICISS) (pp. 336341). IEEE.

7. Dhouib, B., Kahouli, A., \& Abdallah, H. H. (2017, March). Dynamic behavior of grid-connected fixed speed wind turbine based on proportional-integral pitch controller and fault analysis. In 2017 International Conference on Green Energy Conversion Systems (GECS) (pp. 1-7). IEEE.

8. Erlich, I., Wrede, H., \& Feltes, C. (2008). Dynamic behaviour of DFIG-based wind turbines during grid faults. IEEJ Transactions on Industry Applications, 128(4), 396-401.
9. Adouni, A., Chariag, D., Diallo, D., Delpha, C., \& Sbita, L. (2017, October). Statistical analysis of current-based features for dip voltage fault detection and isolation. In IECON 2017-43rd Annual Conference of the IEEE Industrial Electronics Society (pp. 4350-4354). IEEE.

10. Amin, I. K., Uddin, M. N., Hannan, M. A., \& Alam, A. Z. (2019, May). Adaptive Neuro-Fuzzy Controller for Grid Voltage Dip Compensations of Grid Connected DFIG-WECS. In 2019 IEEE International Electric Machines \& Drives Conference (IEMDC) (pp. 2101-2106). IEEE.

11. Gururaj, M. V., \& Padhy, N. P. (2018, August). Fault Ride Through Analysis of Grid Connected Doubly Fed Induction Generator Based Wind System. In 2018 IEEE Power \& Energy Society General Meeting (PESGM) (pp. 1-5). IEEE. 